\title{
Applying Theories of Particle Packing and Rheology to Concrete for Sustainable Development
}

Vivian Wong

Department of Civil Engineering, The

University of Hong Kong,

Hong Kong, China

faiyin@ hku.hk
DOI 10.5592/otmcj.2013.2.3

Research paper

\author{
Ka Wai Chan \\ Department of Civil Engineering, \\ The University of Hong Kong, \\ Hong Kong, China \\ kwchan84@hku.hk
}

\author{
Albert Kwok Hung Kwan \\ Department of Civil Engineering, The \\ University of Hong Kong, \\ Hong Kong, China \\ khkwan@hku.hk
}

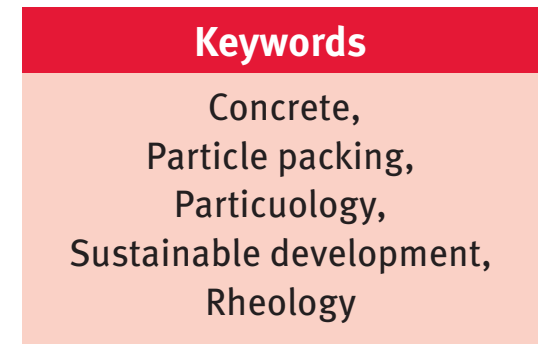

CONCRETE IS ONE OF THE MOST IMPORTANT CONSTRUCTION MATERIALS. HOWEVER, IT IS NOT SO COMPATIBLE WITH THE DEMANDS OF SUSTAINABLE DEVELOPMENT BECAUSE MANUFACTURING OF CEMENT GENERATES A LARGE AMOUNT OF CARBON DIOXIDE AND THEREFORE CEMENT CONSUMPTION PRODUCES A HUGE CARBON FOOTPRINT. Currently, the cement consumption is generally lowered by adding supplementary cementitious materials to replace part of the cement. Nonetheless, in order to maintain performance, there is a limit to such cement replacement by supplementary cementitious materials. To further reduce the cement consumption, the total cementitious materials content has to be reduced. This requires the packing density of the aggregate particles to be maximized so that the amount of voids in the bulk volume of aggregate to be filled with cement paste could be minimized and the surface area of the aggregate particles to be minimized so that the amount of cement paste needed to form paste films coating the surfaces of aggregate particle for rheological performance could be minimized. Such optimization is not straightforward and modern concrete science based on particuology is needed. Herein, a number of new theories regarding particle packing and rheology of concrete, which are transforming conventional concrete technology into modern concrete science, are presented. These theories would help to develop a more scientific and systematic concrete mix design method for the production of high-performance concrete with minimum cement consumption. 


\section{INTRODUCTION}

Sustainable development has become a set of self-evident rules. Although there may be political conflicts between those who wish to preserve the environment and those who support development, sustainability and development are actually not mutually exclusive. In fact, we should strike a balance between development in land use and environmental preservation, which is to improve our quality of life without adversely affecting our environment.

It is the fact that cement rather than concrete is not particularly environmentally friendly. It has been estimated that the production of each ton of cement generates approximately one ton of carbon dioxide into the atmosphere. The excess amount of carbon dioxide is contributing to global warming and the cement industry alone is responsible for about $7 \%$ of all carbon dioxide generated in the world (Meyer, 2009). For the concrete industry to support sustainable development, the primary goal is to use as little cement as possible in concrete production.

There are conventional ways that the concrete industry can increase its compliance with the demands of sustainable development, which includes increasing the use of supplementary cementitious materials, and enhancing the performance of concrete. The cement consumption per unit volume of concrete mix can be reduced by partially substituting cement by various cementitious materials. The most commonly used cement substitutes include fly ash (FA), ground granulated blast-furnace slag (GGBS) and condensed silica fume (CSF), all of which are by-products of the industrial process. By turning the by-products of the industrial process into useful cement substitutes, disposal cost of industrial waste can be avoided and hence value is added to the industrial by-products. Although FA has problems associated with relatively slow rate of strength development, one of the reasons that
FA has still been widely utilized in concrete production is that it reduces the cost of concrete materials as it is generally less expensive than cement (Meyer, 2009). Likewise, GGBS also has the problem of slow strength development. However, partial replacement of cement with GGBS is found to greatly reduce the permeability of concrete as the pore size in cement matrix is reduced through the reaction of GGBS with the calcium hydroxide and alkalis released during the hydration of cement. The reduced in permeability can therefore improve the durability of concrete ( $\mathrm{ACl}$ committee 233, 1995). On the other hand, CSF has become a key ingredient for high-performance concrete as the utilization of CSF in concrete substantially increases the compressive strength and durability of concrete (Langan et al., 2002). Because of its importance for the production of high-performance concrete, its cost has exceeded that of cement (Meyer, 2009).

More recently, it has been suggested that ground glass may also be used as supplementary cementitious materials (Shao et al., 2000). Although it has been known that the alkali in the cement paste would react with the silica in the glass via the alkali-silica reaction (ASR) to produce a gel, which might cause severe damage to the concrete structures due to the ASR induced expansion so that it was found unsatisfactory to use glass as substitutes for coarse aggregates in concrete because of the substantial loss in compressive strength and the excessive ASR induced expansion. Nevertheless, studies have shown that if the glass was grounded to an optimum fine particle size, the pozzolanic behaviour of ground glass would be activated and even overwhelm the ASR (Shao et al., 2000). It was found that a smaller particle size of ground glass would result in a higher activity of pozzolanic reaction, a higher compressive strength in concrete as well as a lower ASR induced expansion.

Apart from reducing cement consumption per unit volume of concrete mix by using supplementary cementitious materials, the overall cement consumption can be dramatically reduced by enhancing the performance of concrete. An increase in concrete strength leads to a reduction of total volume of concrete needed. For example, it has been found that the use of Grade 100 concrete instead of Grade 45 concrete can reduce the volume of concrete needed for the vertical elements by 30\% (Zheng et al., 2009). Since the Grade 100 concrete was produced by adding FA and CSF to the concrete mix rather than increasing the cement used per unit volume of concrete mix, the overall cement consumption dropped significantly due to the large volume of concrete saved. On the other hand, an improvement in concrete durability leads to an increase in service life of concrete structure, thus cutting the costs of future redevelopment and maintenance work. Therefore, improving the performance of concrete can conserve natural resources, reduce overall cement consumption, and remarkably extend the service life of concrete structures and save future redevelopment and maintenance work.

Although enhancing the performance of concrete can help reduce cement consumption and support sustainable development, the enhancement of high-performance concrete (HPC) experiences a number of challenges and many aspects of concrete behaviour are still beyond our comprehension. Consequently, to support sustainable development, it is critical to transform conventional concrete technology to modern concrete science, which enables us to look into the factors governing the performance of concrete so that the performance of concrete can be improved in a more scientific and efficient way. After briefly examining the problems faced by the enhancement of HPC, this article introduces two important topics in particuology of concrete for sustainable development, which are particle 
packing and rheology of concrete. The theories involved in the two topics give insights for future practices in concrete production and may reform the way how concrete mix is designed.

\section{Problems faced by the enhancement of}

\section{high-performance concrete}

The development of HPC aims to enhance performance of concrete in various attributes, which includes strength, workability, dimensional stability and durability. Nowadays, the concrete technology has been advanced so much that with the use of CSF; HPC of compressive strength over $150 \mathrm{MPa}$ can be reached (Langan et al., 2002). Furthermore, the workability of HPC has been improved which enables pumping to a great height. The self-consolidating concrete, a derivative of HPC that is highly workable, flowable and nonsegregating, can spread into confined spaces, fill formwork even to the farreaching corners, and pass through even the most congested reinforcing steel bars without any mechanical compaction but place itself by its own weight. The dimensional stability of concrete has also been improved as the problems of thermal and shrinkage cracking associated with high cement paste volume has been resolved. The durability of concrete structures built today is also good enough to last for more than a century even in marine environment. Although HPC has been ameliorated, there are still some problems associated with the enhancement of HPC.

First, the mix composition of HPC is still primarily designed by trial mixing, which means that the effect of the variation of concrete constituents on the various performance attributes cannot be informed unless tests are carried out. However, the trial mixing process is tedious and time-consuming and is therefore non-economical and inefficient.

Second, even for the same design mix composition of HPC, the variation in physical properties of concrete constituents such as particle size distribution, particle density, packing density and specific surface area would result in fluctuation of performance of HPC. As a result, the quality control of HPC is made difficult. To cover the risk of fluctuation in performance of HPC, concrete structures are often overdesigned, resulting in an increase in production cost and a waste of natural resources. Therefore, what we need is not just high performance, but also high robustness in the production of HPC, which is the ability of concrete to have a consistent performance despite expected or unexpected variations in the properties of concrete constituents.

Third, the various performance attributes of HPC are often contradictory to each other. For example, the use of CSF can substantially increase the strength and durability of concrete. However, the concrete mix with CSF added is often found to be too cohesive, which may not be flowable enough for pumping or workable enough for filling formworks. Another example is related to the use of superplasticizers (SPs). With the use of SPs, water demand for a certain workability requirement can be reduced so that a lower water/binder (cement and cementitious materials) ratio can be adopted to increase the strength of concrete. However, just a slight over dosage of SPs could lead to segregation, bleeding and sedimentation. Therefore, mix optimization for all round HPC is still a challenge.

Having analysed the problems associated with the enhancement of HPC, it is realized that an in-depth understanding of how the various mix parameters would affect the behaviour of concrete is needed for mix optimization and robustness design of concrete. In this regard, The University of Hong Kong has been doing research on particuology of concrete, which aims to develop theories for concrete science. A number of theories regarding particle packing and rheology of concrete have been developed through years of research. These theories help examine what the possible parameters are governing the behaviour of concrete and explain how the variation of these parameters can affect the performance of concrete, as presented herein.

\section{Particle packing of concrete}

\section{Packing density: A key parameter}

affecting the performance of

concrete

A concrete mix may be considered a pack of aggregate particles in a matrix of cement paste. The packing of aggregate particles comprises of aggregates of smaller than $75 \mu \mathrm{m}$ (aggregate powder), $75 \mu \mathrm{m}-5 \mathrm{~mm}$ (fine aggregate), and $5 \mathrm{~mm}-40 \mathrm{~mm}$ (coarse aggregate). Since the matrix of cement paste is more expensive than aggregate and is responsible for large amount of carbon dioxide generated, maximizing the packing density of aggregate particles is generally considered a good strategy both to reduce cost of concrete production and to support sustainable development as less amount of cement paste is required to fill the voids within the aggregate particles. Packing density of aggregate particles can be maximized by proper proportioning the aggregate particles of various sizes (that is to determine the particle size distribution of aggregate particles which gives the highest packing density, which may be controlled by fine to total aggregate ratio) and by widening the particle size range of aggregate particles (such as with the inclusion of powder content of size smaller than $75 \mu \mathrm{m})$.

Actually, packing density optimization is not only beneficial to cost reduction and carbon footprint diminution, but also to concrete performance amelioration as packing density is one of the key parameters governing the behaviour of concrete. For example, the basic principle to improve the dimensional stability of concrete is to reduce 
the cement content or paste volume as it was found that high cement content or large paste volume often led to large thermal expansion or contraction at the early age and large drying shrinkage at the later age (Kwan et al., 2010a). To reduce and control the cement content, it has become a common practice to partially replace cement with supplementary cementitious materials and a numerous laboratory work has been carried out on the effect of these supplementary cementitious materials on heat generation or shrinkage of concrete (Zhang et al., 2003; Kwan et al., 2011a; Kwan et al., 2011b). Nevertheless, maximizing the packing density of aggregate particles can also reduce the amount of cement paste used and hence may improve the dimensional stability of concrete. However, very limited research has been done on the relationship between packing density of aggregate particles and dimensional stability of concrete.

Furthermore, increasing the packing density of binder comprised of cementitious materials and fillers may have positive effect on strength of cement paste/mortar/concrete. It is known that small replacement of cement by CSF can dramatically increase the compressive strength of concrete (Kwan, 2000; Chen et al., 2012). Although the effectiveness of supplementary cementitious materials in improving the strength of concrete is affected by a number of factors such as the amount of reactive silica and the rate of strength development, fineness of particles of the cementitious materials also plays an essential role. It is believed by the authors that supplementary cementitious materials of smaller mean particle size are generally more effective. The high fineness of CSF thus partially explains its high effectiveness in improving the strength of concrete. Since CSF has a mean particle size much smaller than that of cement particles, blending cement with CSF can increase the packing density of binder. With the voids content reduced, the amount of water needed to fill the voids within the cementitious materials in the binder decreases, resulting in a lower water/binder ratio which yields a concrete of higher strength. Apart from blending cement with a single type of cementitious materials, Kwan and $\mathrm{Ng}$ (2004) produced self-consolidating concrete of grade up to 100 by maximizing the packing density of binder through blending different types of cementitious materials. Likewise, Chen and Kwan (2012) increased the packing density and strength of cement paste by incorporating superfine cement.

Apart from strength, increasing the packing density of binder by blending cement with supplementary cementitious materials and fillers may also improve the durability of concrete attributed to reduction of porosity and permeability of cement paste. The reduce in permeability can therefore improve the sulphate resistance of concrete, diminish the potential expansion due to alkali-silica reaction, reduce the penetration of chloride within the concrete and improve the resistance to corrosion of reinforcement.

In fact, packing density is also a key factor influencing the workability and flowability of cement paste/ mortar/concrete. In concrete science, the study of flowing behaviour of concrete falls within the scope of rheology of concrete. In the field of rheology, the flowing behaviour of concrete is often examined by rheological properties such as yield stress and apprarent viscosity instead of workability and flowability studied in concrete technology. Nevertheless, it was shown that yield stress and apparent viscosity exhibit close relationship with flowability measurement of flow spread and flow rate, respectively. Wong et al. (2007) found that by increasing the packing density through blending cement, fly ash and silica fume, the rheological properties of cement paste can be improved. Later, it was found that packing density is not the only factor governing the flowability and rheological properties of cement paste; excess water and solid surface area also play significant roles (Kwan and Wong, 2008; Wong and Kwan, 2008). As packing density is not the only factor determining the flowability and rheological properties of concrete, the various parameters governing the flowing behaviour of concrete will be discussed in more details in the section of rheology of concrete.

From the above, it is evident that packing density is a key factor governing the various attributes of performance of cement paste/mortar/concrete. For the sake of packing density optimization and robustness design of HPC, particle packing models that can accurately predict the packing density of concrete constituents are called for.

Particle packing theories and models There are various structural effects describing how particles of different size are packed together and they have positive or negative effect on packing density. Understanding these structural effects is therefore important to interpretation of packing density of particle systems. Basically, the structural effects include the filling and occupying effects, the more wellknown loosening and wall effects (de Larrard, 1999), and the newly proposed wedging effect (Kwan et al., 2013), as explained herein.

Consider a binary mix of fine and coarse particles, there is an optimum volumetric fraction of fine/coarse particles yielding the maximum packing density. When the volumetric fraction of fine particles is less than optimum, the coarse particles are dominant and the fine particles increase the packing density by filling into the voids within the packing of coarse particles. This is known as the filling effect. On the other hand, when the volumetric fraction of coarse particles is less than optimum, the fine particles are dominant and the coarse particles increase the 


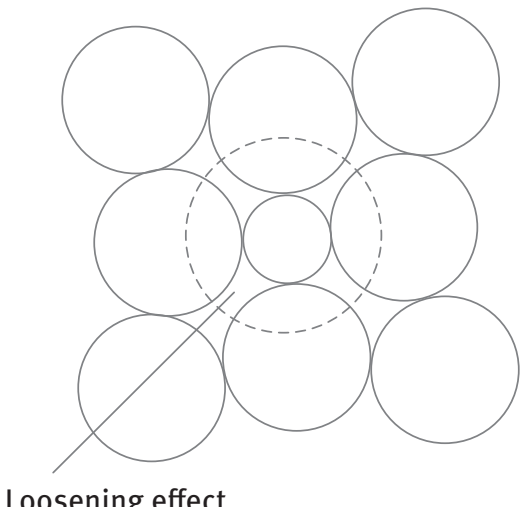

Loosening effect

Figure 1. The loosening effect

packing density by occupying volumes which would otherwise occupied by porous bulk volume of fine particles (i.e. the solid fine particles and voids are replaced by solid coarse particles). This is known as the occupying effect. The filling and occupying effects thus explain why there is an increase in packing density of binder when cement is blended with supplementary cementitious materials or fillers with mean particle size smaller than that of cement. The increase in packing density due to the widening of the particle size range of aggregate particles can also be accounted for, which may be interpreted as successive filling of the voids by smaller aggregate particles (the filling effect) or succesive occupying the porous bulk volume of fine aggregate particles by larger aggregate particles (the occupying effect).

However, the increase in packing density by the filling and occupying

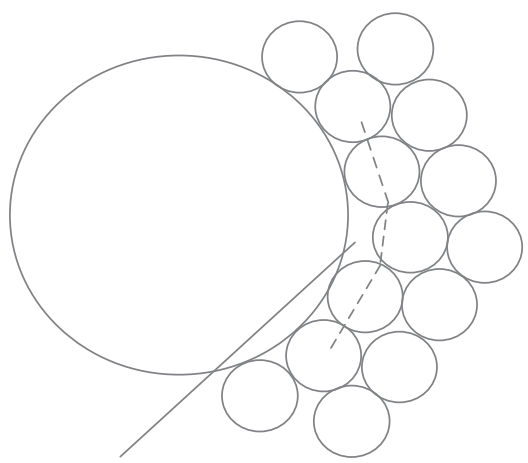

Wall effect

Figure 2. The Wall effect effects may be hindered by the loosening and wall effects, which decrease the packing density of the particle system. When the coarse particles are dominant, the loosening effect occurs when the fine particles are not small enough to fit inside the voids within the coarse particles so that the filling of the fine particles loosens the packing of coarse particles, as illustrated in Figure 1. When the fine particles are dominant, the wall effect occurs when the coarse particles are not large enough so that the coarse particles not only occupy solid volumes in place of porous bulk volume of fine particles but also create additional voids in the vicinity of the periphery of the coarse particles, as depicted in Figure 2. Consequently, the loosening and wall effects depend on the size difference between the fine and coarse particles, which is often expressed in terms of size ratio (the ratio of the size of fine to coarse particles). When size ratio is smaller, the loosening and wall effects are also smaller, and vice versa.

Many particle packing models have been developed, which considered the various structural effects. Some of the particle packing models implicitly take account of the loosening and/or wall effects, such as those developed by Powers (1968), Aïm and Goff (1968), Toufar et al. (1977), Goltermann et al. (1997) and Dewar (1999). In most of the models with loosening and wall effects taken into account, the loosening effect is often explicitly accounted for by a loosening effect parameter, while the wall effect is explicitly considered by a wall effect parameter. Examples include the models developed by Stovall et al. (1986), Yu and Standish (1987) Yu and Standish (1991), Yu et al. (1996), Yu et al. (1997), and de Larrard (1999). With two parameters account for the loosening and wall effects, these models may be collectively called the 2-parameter models.

Figure 3 shows a typical case for binary mix of spherical glass beads, which is extracted from Kwan et al. (2013) for illustration. With the abovementioned structual effects taken into account, the conventional 2-parameter models generally generates packing density curves similar to the discontinuous lines shown in Figure 3, giving a sharp peak at the optimum volumetric fraction, $\mathrm{r}^{*}$, which yields the maximum

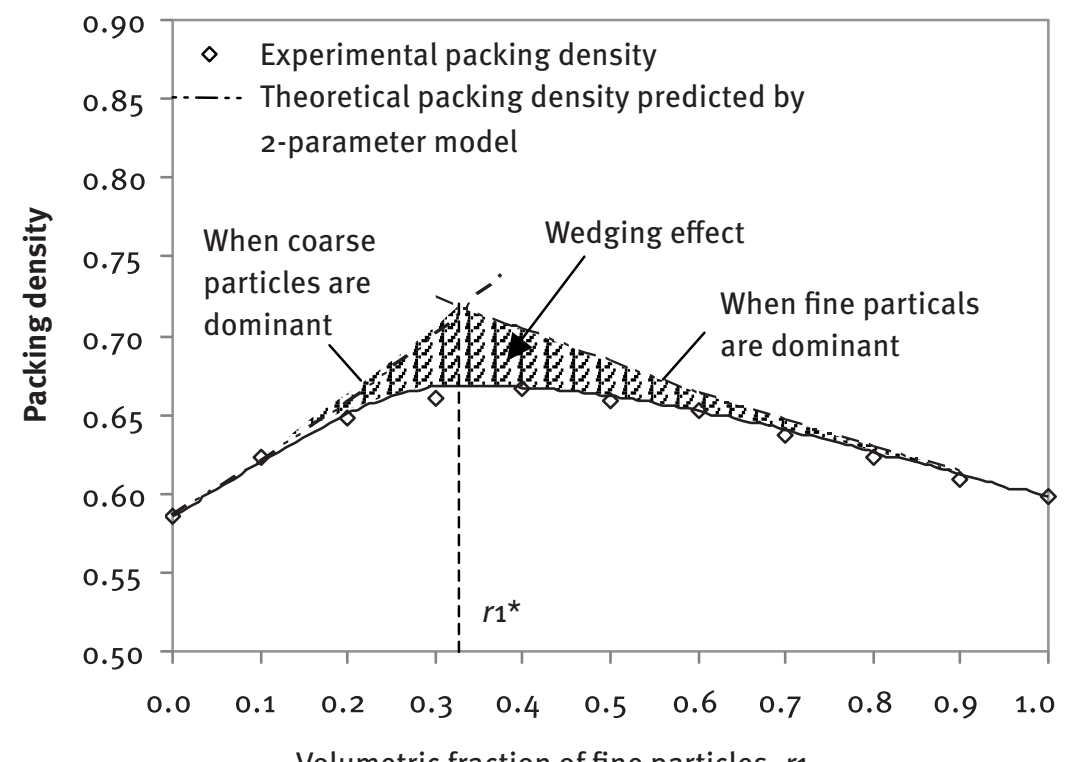

Volumetric fraction of fine particles, $r 1$

Figure 3. Packing density against volumetric fraction of fine particles for a typical binary mix of spherical glass beads 


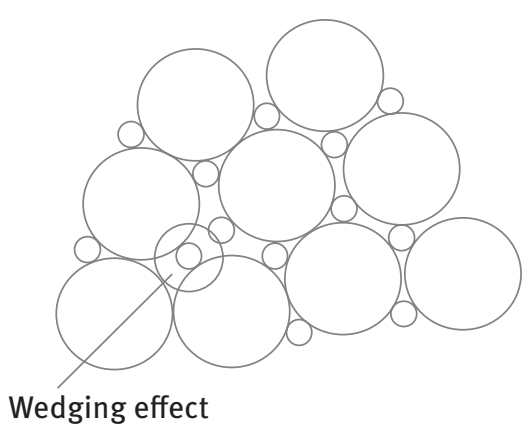

Figure 4 . The wedging effect when the coarse particles are dominant

packing density. In reality, however, the experimental packing densities generally lie on a smooth curve with a blunt peak where the experimental packing densities are always lower than that predicted by the conventional 2-parameter models. From Figure 3, it can be shown that the discrepancies between the experimental and theoretical packing densities are especially large when the volumetric fraction is close to $r 1^{*}$. To unravel the discrepancies, the authors have recently proposed a new structural effect, called the wedging effect. When the coarse particles are dominant, the wedging effect occurs when some isolated fine particles disturb the packing of coarse particles by wedging in the gaps between the coarse particles and are entrapped there instead of filling the voids between the coarse particles, as demonstrated in Figure 4. On the other hand, when the fine particles are dominant, the wedging effect occurs when

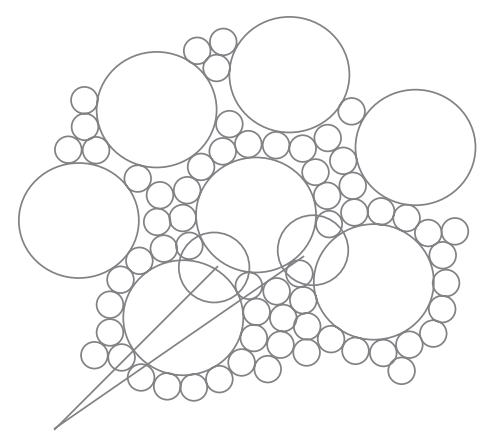

Wedging effect

Figure 5. The wedging effect when the fine particles are dominant some coarse particles are exceptionally close to each other, thus impeding the formation of complete layers of fine particles between them. As a result, additional voids appear at the gaps between the coarse particles, as shown in Figure 5.

By incorporating the wedging effect by an additional parameter, a 3-parameter particle packing model (Kwan et al., 2013) has been developed. The solid line in Figure 5 shows the theoretical packing densities predicted by the 3-parameter model, which provide good agreement with the experimental results. From Figure 3, the differences in packing density between the discontinuous and solid lines, as shaded, are attributed to wedging effect, which is shown to vary with the volumetric fraction.

Meanwhile, a number of modifications were made based on some of the 2-parameters to take account of the various factors affecting packing density. For example, Yu et al. (1996) and Yu et al. (1997) also considered the effect of particle shape and absolute particle size on packing density, respectively. The effect of absolute size of particle is especially significant in packing of very fine particles such as powder. Due to the relatively strong cohesive inter-particle forces such as Van der Waals and electrostatic force, fine particles do not behave individually and agglomerates may form, causing the packing density to be lower (Yu et al., 1997).

Likewise, de Larrard (1999) modified the 2-parameter model of Stovall et al. (1986) by incorporating a compaction index to take account of the effect of compaction and packing process on packing density. Although the newly developed 3-parameter model (Kwan et al., 2013) has not yet accounted for some of the factors influencing packing density such as particle shape, absolute particle size and compaction and packing method, the authors have been working on the modifications. The modified 3-parameter model will be a useful tool for mix optimization and robustness design for HPC in the near future.

\section{Rheology of concrete}

Concrete mix appears to be solid and rigid, but when subjected to an external force, it flows and changes its shape to fit the mould just like liquid. Therefore, concrete exhibits properties that are both solid-like and liquid-like and is a typical yield stress fluid. The rheological properties of yield stress fluid are usually described by yield stress and apparent viscosity, where yield stress is the shear stress that initiates the flow and apparent viscosity describes the resistance to flow that is defined as shear stress divided by shear rate. Rheological models are available for yield stress fluids, such as the Bingham model and the HerschelBulkley model. However, these models are only useful in providing phenomenological descriptions of rheological properties in graphs of shear stress against shear rate, but do not provide an understanding of the behaviour of yield stress fluids. To better understand the rheological behaviour of concrete, it is essential to explore the factors determining its solid-and-liquid-like behaviour so that a scientific approach can be adopted for mix optimization as well as robustness design of HPC.

Robinson (1949) introduced a concept that the specific viscosity is not only proportional to the volume concentration of the suspended solids but also inversely proportional to the volume of free liquid in the suspension. The free liquid is the liquid outside the suspended particles contributing to fluidity, which is not entrapped within the packed particles when the volume concentration is sufficiently high. There exists an upper limit of the volume concentration of the suspension, which is reached when there is just enough liquid to fill the voids between particles. In this case, there is no free liquid 
which makes fluid flow impossible and the suspension becomes a porous solid with infinite viscosity.

Later, Powers (1968) proposed the excess paste theory by postulating that it is the excess paste, the cement paste in excess after filling the voids between the aggregate particles, which contributes to the workability of mortar and concrete. Therefore, increasing the packing density of aggregate particles would for a given volume of cement paste, improve workability; and for a given workability requirement, reduce the amount of cement paste needed. The free liquid introduced by Robinson (1949) and the excess paste proposed by Powers (1968), despite of different names, share the same notion that the excess fluid, no matter in liquid form or in paste form, is one of the major factors affecting the rheological behaviour of fluids with suspended particles such as mortar and concrete.

Apart from packing density and excess fluid, it was found that solid surface area of particles also exhibits great effect on the flowability and rheological properties of cement paste/mortar/ concrete (Kwan and Wong, 2008; Wong and Kwan, 2008; Fung and Kwan, 2010; Kwan and Fung, 2012). For example, for the same amount of excess water, larger surface area generally results in lower flow spread and flow rate and higher yield stress and apparent viscosity for cement paste containing condensed silica fume and/or pulverized fuel ash. This may be explained by the notion of water film thickness as proposed by Kwan et al. (2010b), which may be evaluated by excess water to surface area ratio. Water film thickness has a physical meaning of average thickness of excess water (water that is not entrapped within the voids between particles) coating the constituent particles of cement paste/mortar/concrete. A water film thickness of zero implies that the water content is just enough for filling the voids within the constituent particles while a negative water film thickness has a physical meaning that the water content is not enough for filling the voids within the particles in the mix. It was revealed that an increase in water film thickness would usually increase flow spread and flow rate and decrease yield stress and apparent viscosity, and vice versa (Kwan and Wong, 2008; Wong and Kwan, 2008). Consequently, water film thickness is an important parameter governing the flowability and rheological properties of cement paste/mortar/concrete.

The concept of water film thickness, which incorporates the effects of packing density, water content and surface area, implies that maximum packing density is not necessarily equivalent to optimum packing density for best performance in workability and flowability. For example, the inclusion of very fine particles, such as supplementary cementitious materials and fillers, may increase the packing density of binder but at the same time increase the total surface area of particles in the mix. In this case, addition of very fine particles may increase or decrease the water film thickness, meaning positive or negative effects respectively on workability and flowability of cement paste/mortar/concrete. The increase or decrease in water film thickness depends on whether the effect of increase in excess water or the effect of increase in cohesiveness of the mix contributed by increase in surface area is more dominant. Consequently, to optimize performance in workability and flowability, we should maximize water film thickness but not packing density.

\section{Conclusions}

Enhancing the performance of concrete contributes to sustainability, therefore, high-performance concrete (HPC) can also be regarded as green concrete. However, many aspects of concrete behaviour are still beyond our comprehension, which makes further improvement in performance of HPC challenging. In this regard, it is necessary to transform conventional concrete technology to modern concrete science so that mix optimization of HPC can be performed in a more scientific and efficient way. To do so, we have to look into and understand the factors governing the performance of concrete. This article introduces two major topics in particuology for concrete science, which are particle packing and rheology of concrete. A number of factors affecting the performance of concrete have been identified and explained, such as packing density, excess water and surface area of particles. The theories and models involved in particle packing and the notion of water film thickness have also been expounded.

The University of Hong Kong has been working on particle packing and rheology modelling. It is envisaged that the developed and modified models can be incorporated in computer software that the various parameters governing the performance of concrete such as packing density and water film thickness can be computed from inputs such as particle size distribution, particle density and surface area. This software can help perform mix optimization and improve quality control in response to variations in physical properties of mix constituents. In this case, we can slash carbon dioxide emission and support sustainable development by enhancing the performance of HPC. 


\section{References}

ACl Committee 233 (1995), “Ground granulated blast-furnace slag as a cementitious constituent in concrete", $\mathrm{ACl}$ committee report, $\mathrm{ACl}$ 233R-95, American Concrete Institute, 1 October.

Aïm, R.B. and Goff, P.L. (1968), “Effet de paroi dans les empilements désordonnés de sphères et application à la porosité de mélanges binaires”, Powder Technology, Vol. 1 No. 5, pp. 281-290.

Chen, J.J., Fung, W.W.S. and Kwan, A.K.H. (2012), "Effects of CSF on strength, rheology and cohesiveness of cement paste", Construction and Building Materials, Vol. 35, pp. 979-987.

Chen, J.J. and Kwan, A.K.H. (2012), "Superfine cement for improving packing density, rheology and strength of cement paste", Cement and Concrete Composites, Vol. 34 No. 1, pp. 1-10.

de Larrard, F. (1999), Concrete Mixture Proportioning: A Scientific Approach, E \& FN Spon, London.

Dewar, J.D. (1999), Computer Modelling of Concrete Mixtures, E \& FN Spon, London.

Fung, W.W.S. and Kwan, A.K.H. (2010), “Role of water film thickness in rheology of CSF mortar", Cement and Concrete Composites, Vol. 32 No. 4, pp. 255-264.

Goltermann, P., Johansen, V. and Palbøl, L. (1997), "Packing of aggregates: An alternative tool to determine the optimal aggregate mix”, $\mathrm{ACl}$ Materials Journal, Vol. 94 No. 5 , pp. 435-443.

Kwan, A.K.H. (2000), "Use of condensed silica fume for making high-strength, selfconsolidating concrete", Canadian Journal of Civil Engineering, Vol. 27 No. 4, pp. 620-627.

Kwan, A.K.H. and Ng, I.Y.T. (2004), “Grade 80100 self-consolidating concrete for Hong Kong”, Transactions, Hong Kong Institution of Engineers, Vol. 11 No. 2, pp. 1-7.

Kwan, A.K.H. and Wong, H.H.C. (2008), "Effects of packing density, excess water and solid surface area on flowability of cement paste", Advances in Cement Research, Vol. 20 No. 1, pp. 1-11.

Kwan, A.K.H., Ng, P.L. and Fung, W.W.S. (2010a), "Research directions for high-performance concrete" in Proceedings, Infrastructure Solutions for Tomorrow HKIE Civil Division Conference 2010 in Hong Kong, China,
2010, available at: http://hkie.cvd. annualconference.i-wanna.com/download.

Kwan, A.K.H., Fung, W.W.S. and Wong, H.H.C. (2010b), "Water film thickness, flowability and rheology of cement-sand-mortar", Advances in Cement Research, Vol. 22 No. 1, pp. 3-14.

Kwan, A.K.H., Fung, W.W.S., Chen, J.J. and Ng, P.L. (2011a), “Heat generation of curing fly ash concrete at different $\mathrm{w} / \mathrm{cm}$ ", $\mathrm{ACl}$ Materials Journal, Vol. 108 No. 3, pp.307-315

Kwan, A.K.H., Chen, J.J., Fung, W.W.S. and Ng, P.L. (2011b), "Effects of silica fume on heat generation of curing concrete", $\mathrm{ACl}$ Materials Journal, Vol. 108 No. 6, pp. 655-663.

Kwan, A.K.H. and Fung, W.W.S. (2012), “Roles of water film thickness and SP dosage in rheology and cohesiveness of mortar", Cement and Concrete Composites, Vol. 34 No. 2, pp. 121-130.

Kwan, A.K.H., Chan, K.W. and Wong, V. (2013), "A 3-parameter particle packing model incorporating the wedging effect”, Powder Technology, Vol. 237, pp. 172-179.

Langan, B.W., Weng, K. and Ward, M.A. (2002), "Effect of silica fume and fly ash on heat of hydration of Portland cement", Cement and Concrete Research, Vol. 32 No. 7, pp. 10451051.

Meyer, C. (2009), "The greening of the concrete industry”, Cement and Concrete Composites, Vol. 31 No. 8, pp. 601-605.

Powers, T.C. (1968), The Properties of Fresh Concrete, John Wiley \& Sons, New York.

Robinson, J.V. (1949), “The viscosity of suspensions of spheres", Journal of Physical Chemistry, Vol. 53 No. 7, pp. 1042-1056.

Shao, Y., Lefort, T., Moras, S. and Rodriguez, D. (2000), "Studies on concrete containing ground waste glass", Cement and Concrete Research, Vol. 30 No. 1, pp. 91-100.

Stovall, T., de Larrard, F. and Buil, M. (1986), "Linear packing density model of grain mixtures”, Powder Technology, Vol. 48 No. 1, pp. 1-12.

Toufar, W., Klose, E. and Born, M. (1977), "Berechnung der packungsdichte von korngemischen”, Aufbereitungs-Technik, Vol. 18 No. 11, pp. $603-608$.

Wong, H.H.C. and Kwan, A.K.H. (2008), "Rheology of cement paste: role of excess water to solid surface area ratio", Journal of Materials in Civil Engineering, American
Society of Civil Engineers, Vol. 20 No. 2, pp. 189-197.

Wong, H.H.C., Ng, I.Y.T., Ng, P.L. and Kwan, A.K.H. (2007), “Increasing packing density through blending cement, fly ash and silica fume to improve cement paste rheology" in ACI Special Publication SP-242-17, 9th CANMET/ACI International Conference on Fly Ash, Silica Fume, Slag and Natural Pozzolans in Concrete in Warsaw, Poland, 2007, pp. 221-225.

Yu, A.B. and Standish, N. (1987), "Porosity calculations of multi-component mixtures of particles", Powder Technology, Vol. 52 No. 3, pp. 233-241.

Yu, A.B. and Standish, N. (1991), "Estimation of the porosity of particle mixtures by a linear-mixture packing model”, Industrial \& Engineering Chemistry Research, Vol. 30 No. 6, pp. $1372-1385$.

Yu, A.B., Zou, R.P. and Standish, N. (1996), "Modifying the linear packing model for predicting the porosity of nonspherical particle mixtures”, Industrial \& Engineering Chemistry Research, Vol. 35 No. 10, pp. 37303741.

Yu, A.B., Bridgwater, J. and Burbidge, A. (1997), "On the modelling of the packing of fine particles”, Powder Technology, Vol. 92 No. 3, pp. $185-194$.

Zhang, M.H., Tam, C.T. and Leow, M.P. (2003), "Effect of water-to-cementitious materials ratio and silica fume on the autogenous shrinkage of concrete", Cement and Concrete Research, Vol. 33 No. 10, pp. 1687-1694.

Zheng, H.W., Chan, F.W.Y. and Kwan, A.K.H. (2009), “High-performance concrete for green construction" in Proceedings, 7 th International Conference on Tall Buildings in Hong Kong, China, 2009, pp. 163-170. 